\section{Espacios de riesgos y amenazas naturales en Santiago de Chile: el río Mapocho como geosímbolo de desastres en el siglo XVIII}

\author{
Spaces of natural risks and threats in \\ Santiago, Chile: the Mapocho River as a \\ geosymbol of disasters in the 18th century
}

\author{
Andrea Noria Peña \\ Universidad Autónoma de Chile \\ Santiago, Chile \\ Andrean.noriap@gmail.com \\ (iD) 0000-0002-9655-5857
}

\section{Información del artículo \\ Recibido: 18 mayo 2020 \\ Revisado: 11 noviembre 2020 \\ Aceptado: 10 febrero 2021}

\begin{abstract}
RESUMEN
Esta investigación analiza la relación de la ciudad de Santiago de Chile con el río Mapocho como espacio de riesgos y amenazas durante el siglo XVIII. Para ello, se observan las respuestas de la población y de las autoridades civiles y eclesiásticas frente a los peligros del río cuando la ciudad era el escenario de diversas amenazas como las enfermedades, las sequías, las lluvias, las inundaciones fluviales y los deshielos cordilleranos. Hemos utilizado varias fuentes como relatos de viajeros, comunicaciones oficiales, informes técnicos, los debates del Cabildo de Santiago, y obras impresas contemporáneas al estudio. Los resultados permiten concluir que los episodios de inundaciones, sequías y brotes epidémicos transformaron al río Mapocho en un geosímbolo de desastres en el imaginario social e institucional de la ciudad.
\end{abstract}

PALABRAS CLAVE: Santiago de Chile, Río Mapocho, Siglo XVIII, Riesgos, Amenazas.

\begin{abstract}
This research analyzes the relationship between the city of Santiago de Chile and the Mapocho River as a space for risks and threat during the 18th century. In order to do this, we observed the responses of the population and the civil and ecclesiastical authorities against the dangers of the river when the city was the scene of several threats such as diseases, droughts, rains, fluvial floods and the melting of the Cordillera. We have used various sources such as travelers' reports, official communications, technical reports, the debates of the Cabildo de Santiago, and printed works contemporary to the studio. The results allow us to conclude that the episodes of floods, droughts and epidemic outbreaks transformed the Mapocho River into a geosymbol for disasters in the social and institutional images of the city.
\end{abstract}


Espaços de riscos e ameaças naturais em Santiago do Chile: o rio Mapocho como símbolo geográfico de desastres no século XVIII

\section{SUMÁRIO}

Esta pesquisa analisa a relação da cidade de Santiago do Chile com o rio Mapocho como espaço de riscos e ameaças durante o século XVIII. Para isso, observam-se as respostas da população e das autoridades civis e eclesiásticas aos perigos do rio, quando a cidade foi palco de várias ameaças como doenças, secas, chuvas, cheias de rios e derretimentos de montanhas. Para o estudo, utilizamos várias fontes, como relatos de viajantes, comunicações oficiais, relatórios técnicos, os debates do Cabildo de Santiago e obras impressas contemporâneas. Os resultados permitem concluir que os episódios de enchentes, secas e surtos epidêmicos transformaram o rio Mapocho em um geossimbolo de desastres no imaginário social e institucional da cidade.

PALAVRAS-CHAVE: Santiago de Chile, Rio Mapocho, Século 18, Riscos, Ameaças.

\section{Espaces de risques et menaces naturels à Santiago du Chili: le fleuve Mapocho comme géosymbole des catastrophes au XVIIIe siècle}

\section{RÉSUMÉ}

Cette recherche analyse la relation entre la ville de Santiago du Chili et le fleuve Mapocho en tant qu'espace de risques et de menaces au XVIIIe siècle. Pour lui, vous pouvez voir la réponse de la population et des autorités civiles et ecclésiastiques aux dangers du fleuve alors que la ville était le théâtre de divers dangers tels que maladies, séquelles, rivières, crues fluviales et crues des montagnes. Nous avons utilisé diverses sources telles que des rapports de voyage, des communications officielles, des rapports techniques, des débats dans le Cabildo de Santiago et des imprimés contemporains dans l'étude. Les résultats permettent de conclure que les épisodes d'inondations, de séquences et d'épidémies transforment la rivière Mapocho en un géosymbole de catastrophes dans l'imaginaire social et institutionnel de la ville.

MOTS CLÉS: Santiago du Chili, Rivière Mapocho, 18e siècle, Risques, Menaces.

\section{Spazi di rischi e minacce naturali a Santiago del Cile: il fiume Mapocho come geosimbolo di catastrofi nel XVIII secolo}

\section{SOMMARIO}

Questa ricerca analizza il rapporto della città di Santiago del Cile con il fiume Mapocho come spazio di rischi e minacce durante il XVIII secolo. Per fare ciò si osservano le risposte della popolazione e delle autorità civili ed ecclesiastiche ai pericoli del fiume quando la città era teatro di varie minacce come malattie, siccità, piogge, alluvioni fluviali e scioglimenti montuosi. Per lo studio abbiamo utilizzato varie fonti come resoconti di viaggiatori, comunicazioni ufficiali, rapporti tecnici, dibattiti del Cabildo de Santiago e opere a stampa contemporanee. I risultati ci consentono di concludere che gli episodi di inondazioni, siccità ed epidemie hanno trasformato il fiume Mapocho in un geosimbolo di disastri nell'immaginario sociale e istituzionale della città.

PAROLE CHIAVE: Santiago del Cile, Fiume Mapocho, XVIII secolo, Rischi, Minacce. 


\section{Introducción}

En 1784 apareció publicado en Lima un romance sobre la inundación de Santiago de Chile ocurrida el 16 de junio de $1783^{1}$. La autora de aquella composición lírica se daría a conocer a mediados del siglo XIX y correspondería a una monja del Convento de las Carmelitas, Tadea García de la Huerta, conocida como sor Tadea de San Joaquín. El escrito sería uno de los mayores exponentes de las inundaciones del río Mapocho durante el período colonial y referencia obligatoria para el estudio histórico y social de este tipo de escenarios; más aún tomando en cuenta que el desbordamiento del río y la anegación de la ciudad de Santiago en ese año se convertirían en uno de los episodios de extremismo climático más importante durante el siglo XVIII en la Capitanía General de Chile.

No fue el único caso. En medio de una sublevación indígena en el año de 1723, las aguas del Mapocho se salieron de su cauce a raíz de fuertes lluvias el 17 de mayo. Una vez más, el sistema defensivo creado para contener los desbordamiento del principal río de la ciudad de Santiago cedió ante la fuerza del caudal de las aguas. Estos escenarios fueron comunes en la Capitanía General de Chile desde el siglo XVI. Al mismo tiempo, los espacios de aquel río arroparon las desavenencias de los habitantes de Santiago por el recurso hídrico en tiempos de sequía y por la calidad del agua frente a episodios de enfermedades.

El proceso de conquista y colonización hispanoamericano supuso la búsqueda de zonas de asentamiento con acceso a los recursos naturales estratégicos que permitiesen llevar a cabo una efectiva empresa de ocupación. Dentro del mismo contexto, los ríos se convirtieron en espacios que garantizaban el uso de uno de estos recursos, además se plantearon como medios de movilización y conexión, como centros nodales en las redes intrarregionales, como espacios de socialización y también desempeñaron un rol importante en la organización y estructuración de los diversos centros urbanos y rurales.

De esta manera, los ríos se han convertido en geosímbolos ${ }^{2}$ para las poblaciones que conviven con él: medio de comunicación, espacio de recreación, fuente de alimentación y de abastecimiento de agua. Su contundencia ha permitido que además se identifique rápidamente con la construcción no solo material sino simbólica del territo-

\footnotetext{
1. El impreso de sor Tadea tuvo una reimpresión en 1862. Es la versión utilizada en esta investigación. Huerta García, 1862.

2. Bonnemaison, 1992, 71, definió los geosímbolos como aquellos elementos o espacios que adquieren significación simbólica y cultural, lo cual permite a su vez afianzar los códigos identitarios de las sociedades y se constituyen en portadores de memoria.
}

rio. Los ríos forman parte de las ciudades y las ciudades forman parte de los ríos.

Por tanto, proponemos que la capacidad de moldear la ciudad colonial en términos materiales y también simbólicos permitió que los ríos se construyeran, al mismo tiempo, como espacios de riesgos y amenazas. Para el caso del río Mapocho, planteamos que durante el siglo XVIII este tipo de significación de la corriente predominó y trasladó los códigos de identificación con el elemento natural al plano del peligro. Sus usos cotidianos como surtidor de aguas para el riego y para el consumo derivaron en una referencia a las disputas por la escasez hídrica y a su consideración como fuente de enfermedades, y la más llamativa durante la colonia, como espacio de riesgo cuando se sucedían las inundaciones fluviales por la anegación de la ciudad.

\section{Antecedentes de investigación y metodología}

El acceso al recurso hídrico y el establecimiento de vías de comunicación se han convertido desde muy temprano en dos variables esenciales a la hora del poblamiento de diversas cuencas. Imágenes, percepciones, energía, circulación y movimiento han caracterizado a los ríos como agentes históricos en tanto el papel que juegan en las sociedades lo determina la manera en que estas conviven y piensan en los cursos de agua, y el valor que estos tienen para las estructuras económicas y productivas pero también sociales y culturales.

Los estudios en Chile en torno a los ríos como agentes históricos, las amenazas naturales y los desastres asociados a ellas son escasos. Para este último caso, no obstante, encontraron un espacio de discusión a partir de la década de 1980, desde los estudios históricos sobre el impacto de fenómenos naturales, de la mano de las investigaciones del historiador Rolando Mellafe. Sus investigaciones en torno al "acontecer infausto" de Chile y la relación con la identidad chilena han marcado una bibliografía de obligatoria referencia para aquellos que se dedican a estas temáticas. Su perspectiva desde la historia de las mentalidades generó nuevos espacios de discusión ${ }^{3}$. Los

\footnotetext{
3. Mellafe, 1980, 125. El autor concentró sus estudios en desastres asociados a amenazas de origen natural como terremotos, lluvias torrenciales y de inundaciones, sequías prolongadas, epidemias y plagas entre 1520 y 1906. Entre los resultados obtenidos, Mellafe señala que de los 386 años computados ocurrieron 282 desastres, es decir, un $73 \%$ del total. Este resultado, no obstante, se obtiene a partir de asumir una relación sinonímica entre la amenaza natural y el desastre. Desde los estudios históricos de los desastres, estos son definidos como procesos que develan condiciones críticas preexistentes que son detonados, en el caso de las amenazas naturales, por la presencia en el tiempo y en el espacio de un fenómeno natural potencial-
} 
sismos se convirtieron en los máximos representantes de la caracterización de ese acontecer, y en conjunto con las epidemias, las temáticas más abordadas dentro del amplio espectro de este tipo de estudio. No obstante, ya desde el siglo XIX, el trabajo de Benjamín Vicuña Mackenna ${ }^{4}$ se convirtió en una obra de referencia que se mantiene hasta la actualidad para el estudio de los eventos climáticos durante el período de la monarquía española y como una fuente primaria fundamental para este tipo de investigaciones durante el primer siglo republicano.

Para el caso de los estudios históricos sobre el río Mapocho, entre las investigaciones se encuentra el trabajo de Simón Castillo Fernández ${ }^{5}$ que analiza la dinámica del espacio público y la intervención urbana en la ciudad de Santiago entre 1885 y 1918 a partir del río y sus riberas como un lugar privilegiado para dar cuenta de estos procesos. El estudio de Rubén Stehberg y Gonzalo Sotomayor ${ }^{6}$ ofrece nueva evidencia a partir del debate etnohistórico y arqueológico sobre el rol que desempeñó el Mapocho durante la ocupación incaica. Y en sintonía con las obras hidráulicas de contención a partir de evidencia arqueológica e histórica, la investigación de Alfredo Gómez Alcorta, Claudia Prado Berlien y Francisco José Ocaranza Bosio ${ }^{7}$ se enfoca en contextualizar la construcción de los tajamares del Mapocho, evidenciando los esfuerzos de la sociedad colonial por atender la problemática de las inundaciones y los riesgos climáticos.

En este sentido, el objetivo general de esta investigación es comprender el rol que desempeñó el río Mapocho como espacio de riesgos y amenazas naturales durante el siglo XVIII a partir de la relación defensiva que estableció la ciudad de Santiago frente a procesos naturales extremos como las lluvias torrenciales y las inundaciones fluviales, como un espacio de riesgo biológico y como un lugar de desencuentro en tiempos de sequías.

Para alcanzar este objetivo se recurrió a diversas fuentes, entre los cuales destacamos los escritos de viajeros y cronistas; actas del cabildo de Santiago, documentos gubernamentales localizados en los fondos Capitanía General y Real Audiencia del Archivo Nacional Histórico de Chile, los manuscritos del Fondo Medina de la Biblioteca Nacional de Chile y la Audiencia de Chile del Archivo General de Indias. La información se sistematizó en dos etapas.

mente destructor y que, al mismo tiempo, se articula con condiciones de vulnerabilidad. Véanse los trabajos de García Acosta, 2004, 124-142. Altez, 2016; 2009, 111-128.

4. Vicuña Mackenna, 1877.

5. Castillo Fernández, 2014

6. Stehberg y Sotomayor, 2012, 85-149.

7. Gómez Alcorta et. al., 2012, 275-315.
En primer lugar, identificamos episodios específicos a través de las actas del cabildo y documentación diversa obtenida en investigaciones preliminares sobre temas con algún grado de vinculación, lo que nos permitió realizar el análisis de acuerdo con el tipo de amenaza natural. De igual manera, a partir de las sesiones sostenidas por los cabildantes de Santiago agrupamos las disposiciones de la ciudad para enfrentar las contingencias detonadas por las amenazas que tuvieron lugar durante el siglo XVIII, dirigidas especialmente a la concreción de obras hidráulicas que permitiesen atajar los inconvenientes que dejaban las lluvias y garantizar la circulación del agua. Esta información la cruzamos con datos provenientes de la construcción de dichas obras y los diversos informes emitidos por las autoridades que cubrían las temáticas de costos, tiempos y detalles técnicos sobre dichas obras.

En segundo lugar, categorizamos la información obtenida a partir de las prácticas que se desplegaron para atender los efectos de estos episodios (técnicas/ tecnológicas y simbólicas/religiosas). Esto nos condujo a identificar el tipo de relación que se estableció con el río Mapocho según las amenazas, lo que permitió agrupar, por un lado, las inundaciones y lluvias; y por otro lado, las sequías y epidemias.

\section{Riesgos y amenazas en la Capitanía General de Chile}

Con la expansión europea del siglo XV, la búsqueda de nuevas rutas comerciales y riquezas condujo a la navegación del Atlántico y la llegada al espacio que posteriormente ellos conocerían como las Indias Occidentales. Este proceso se tradujo en metales preciosos, mercadería y tierras adecuadas para el desarrollo agrícola. En este sentido, los intereses económicos condicionaron los asentamientos en aquellos parajes que significaban espacios geográficos heterogéneos, con condiciones climáticas y ecosistemas diferentes a los que estaban acostumbrados. Por lo que, y en armonía con el postulado de que la producción de riqueza también produce riesgos ${ }^{8}$, la sociedad colonial cimentó las bases de contextos vulnerables y amenazas naturales ${ }^{9}$.

A pesar de ello, las huestes conquistadoras comprendieron rápidamente que las condiciones naturales de las Indias Occidentales representaban un peligro para ellos, como se evidencia en el interés por las amenazas

\footnotetext{
8. Beck, 2006, 29.

9. Sobre la vulnerabilidad frente a amenazas naturales durante el período coIonial, véase Altez, 2016, 37-80; 2014, 159-177.
} 
dentro del esquema de los cuestionarios y relaciones de Indias. Sin embargo, no representaron un papel hegemónico, según se advierte en el trabajo de Ana Olivera en el cual se determinó que para el siglo XVI solamente representaba un $15 \%$ del contenido en contraposición con el siglo XVIII que aumentó en un $35 \%{ }^{10}$.

Por otro lado, el contacto hispano-indígena conllevó, indefectiblemente, a que se consolidaran amenazas antropogénicas características de la sociedad colonial, que si bien en muchos espacios coloniales desaparecieron como amenazas una vez superado el período de conquista y buena parte de la colonización, en el caso de la Capitanía General de Chile se mantuvieron por mucho más tiempo. La confrontación con los indígenas fue el factor antrópico más común y dentro de este tipo de amenazas la más extendida en estos parajes.

Para el caso de las amenazas naturales, estas se han clasificado desde las ciencias naturales de acuerdo con el tipo de fenómeno que las origina. De esta manera, encontramos las hidrometeorológicas cuyo rango abarca lluvias, huracanes, sequías, tornados, heladas, por ejemplo, y otras amenazas derivadas de aquellas como las inundaciones pluviales, fluviales y costeras, incendios forestales y aludes torrenciales. Otro tipo de amenaza son las geológicas, entre las cuales se encuentran los sismos y los movimientos de masa, asociadas igualmente a tsunamis, corrimiento de laderas inestables, deslizamientos, licuación de suelos, sedimentación. Y, por último, en el espectro de las amenazas biológicas que predominaron para el período colonial se encuentran las plagas (langostas, gusanos, ratones) y virus, identificados comúnmente como viruelas, calenturas, disenterías, fiebre amarilla, sarampión, pestes ${ }^{11}$. Este último tipo de peligro fue el más recurrente y mortífero de todos durante el período de estudio.

En el territorio que sería conocido como chile, la empresa conquistadora se vio enfrentada a estas condiciones, muchas de ellas desconocidas para todos sus impulsores. Desde los primeros contactos con el Estrecho de Magallanes en 1520 los obstáculos con los que se vieron enfrentados durante la travesía como el frío acérrimo, la falta de mantenimientos y agua dulce, naufragios y deserciones, condujeron a establecer un imaginario negativo de aquel espacio a través de relaciones como las de Antonio Pigafetta y Ginés de Mafra ${ }^{12}$. Pero más importante que las expediciones magallánicas para la conformación de dicho imaginario, fue la expedición

\footnotetext{
10. Olivera Poll, 1988, 242.

11. Altez, 2014, 166-167.

12. Onetto, $2017,37$.
}

de conquista de Diego de Almagro (1535-1536). Para emprender la travesía de lo que serían las tierras chilenas decidió trazar una ruta a través de la cordillera de los Andes, lo que le costaría grandes pérdidas humanas bajo condiciones climáticas adversas ${ }^{13}$.

Ya luego, con la expedición efectiva de Pedro de Valdivia en 1541, estas condiciones también formaron parte del proceso de asentamiento. Días con fuertes lluvias e inclementes inviernos fueron descritos en las primeras cartas del conquistador extremeño ${ }^{14}$. Esos eventos y otros como plagas de langostas, ratones, sequías, epidemias y terremotos se convirtieron en amenazas para aquellos contextos. En todo caso, serían los terremotos, las epidemias y las inundaciones fluviales las amenazas naturales más temidas por la población. Otras, de índole antrópico, como los ataques indígenas, la piratería e incendios también pasaron a engrosar un ambiente de riesgo y una población vulnerable.

Los terremotos, por la ubicación de Chile en el Cinturón de Fuego del Pacífico, el cual concentra algunas de las más importantes zonas de subducción, desempeñaron un papel decisivo en la relación construida en torno a los fenómenos naturales. Entre ellos, los ocurridos en 1647, 1657, 1730 y 1751 fueron de los más representativos para el período colonial ${ }^{15}$, cuyo impacto se acrecentó al ir de la mano de una articulación de otras amenazas como epidemias e inundaciones. Estos escenarios detonaron procesos de desastres $\mathrm{y}$, sin duda, se insertaron en el imaginario colectivo de aquel reino.

$\mathrm{Al}$ igual que los temblores de tierras, las epidemias causaron gran temor entre la población por ser una de las amenazas más mortíferas que diezmaron gran parte de las comunidades, especialmente los indígenas ${ }^{16}$. Para el caso de la Gobernación de Chile se registraron

13. En efecto, desde el Cuzco, el adelantado Almagro se embarcó el 3 de julio de 1535 en una expedición hacia el sur del imperio incaico. Aquel reconocimiento de un territorio aislado por barreras naturales dejó un sinsabor en los implicados, tras su retorno al Perú. Las circunstancias de los dos viajes, más las condiciones con las que convivieron mientras estuvieron en aquellos territorios, consolidarían los cimientos del incipiente discurso de una tierra de catástrofes (Onetto, 2017). Fuertes temporales, gran cantidad de nieve y la escasez de alimentos, sin duda, liderarían las dificultadas plasmadas por los expedicionarios. El cronista de las Indias, Gonzalo Fernández de Oviedo y Valdés, fue uno de los primeros en relatar el periplo de Almagro y su gente, entre 1535 y 1557, reflejando aquellas características que les serían adjudicadas a esas tierras: un suelo infértil, sin metales preciosos y poco poblada. Véase: Fernández de Oviedo y Valdés, 1855, 252-289.

14. Pedro de Valdivia, Carta al Emperador Carlos V, La Serena, 4 de Septiembre de 1545. Publicada en Gay, 1846, 53.

15. Palacios Roa, 2015.

16. Sobre las diversas enfermedades y epidemias registradas en las Indias Occidentales y en el continente americano en general durante la época colonial existe una bibliografía bastante amplia. Al respecto, se pueden consultar: Crosby, 1988, 220; 1972, 47-58. Newman, 1976, 671. Kiple, 1993, 497-504. 
desde muy temprano múltiples episodios y fueron continuos a lo largo del período colonial. En muchos casos se presentaron brotes significativos después de un proceso geológico como terremotos o climáticos, tras inundaciones y, especialmente, sequías ${ }^{17}$.

Si bien en estos territorios la manifestación de terremotos ha sido un factor determinante en la construcción identitaria devenida con la época republicana, y motivo de constantes preocupaciones y usos políticos en el contexto monárquico, el extremismo climático que abarca ambos espectros de los tipos de amenazas, a partir de la presencia de lluvias torrenciales, inundaciones fluviales y sequías, también generó debates y mecanismos que se tradujeron en estrategias y prácticas que buscaron atender la emergencia y, en algunos casos, evitar futuros daños, mucho más evidente para las lluvias e inundaciones que en el caso de las sequías ${ }^{18}$.

Esta variedad de fenómenos naturales se articuló, al mismo tiempo, con espacios de riesgos. Estos espacios y la vulnerabilidad de la misma sociedad dieron cabida a la construcción social de las amenazas naturales. Los ríos, por ejemplo, son indicadores de este proceso, y se asociaron a amenazas hidrometeorológicas. Lluvias torrenciales y deshielos cordilleranos conllevaron a inundaciones fluviales y pluviales, una de las amenazas más temidas, en especial en la ciudad de Santiago. En tiempos de sequías, por su parte, se veían afectados ya que disminuía el caudal y se percibía como foco de enfermedades. Como fuente de abastecimiento y aprovisionamiento de agua para el regadío y el consumo, estos escenarios generaban tensión entre la población.

El río Mapocho fue uno de los ríos más importantes durante el período colonial en la Capitanía General de Chile. Este espacio de asentamiento estratégico para la Corona se convirtió en el eje articulador de la capital de aquel Reino y permitió la planificación urbana de Santiago. Al mismo tiempo, el valor social, económico y urbano que tuvo para la ciudad se vio constantemente intervenido por su consolidación como un espacio de riesgos, que amenazaba el desenvolvimiento cotidiano de los vecinos y acrecentaba las desigualdades entre los mismos.

La ciudad de Santiago se construyó en una cuenca que forma parte de un sistema compuesto por la Cordillera de los Andes, la Depresión Intermedia y la Cor-

\footnotetext{
17. Urrutia y Lanza, 1993.

18. Noria Peña, 2018.
}

dillera de la Costa. La Depresión Intermedia, que se extiende desde el cordón de Chacabuco hasta el valle longitudinal, es la que contiene la cuenca de Santiago, que forma parte de la hoya hidrográfica del río Maipo. Se encuentra, por el poniente y el oriente respectivamente, circunscrita por la Cordillera de la Costa y las primeras estribaciones de la precordillera andina. Al norte se advierte el cordón de Chacabuco y al sur los cerros de Paine. Con una extensión de $80 \mathrm{~km}$ de norte a sur y $35 \mathrm{~km}$ de ancho, esta cuenca fue importante para el proceso de asentamiento colonial. Varios de sus elementos, como los antiguos cordones cordilleranos transversales, que en la actualidad dan forma a cerros islas como el Santa Lucía, desempeñaron un papel importante durante el proceso de asentamiento y en la planificación urbana de la misma ${ }^{19}$.

De igual manera, esta ubicación determina dos tipos de climas: Templado de tipo Mediterráneo y Frío de altura. Uno, caracterizado por una prolongada estación seca, condicionada por el Anticiclón del Pacífico, e inviernos lluviosos que concentran la mayor parte de las precipitaciones anuales. Otro, distinguido por un frío de altura que se localiza en la Cordillera de los Andes sobre los 3.000 metros, con bajas temperaturas y precipitaciones sólidas, lo cual garantiza una acumulación de nieve y campos de hielo permanente en cumbres y quebradas ubicadas en dicha zona. Además, es posible observar en esta cuenca diferencias climáticas locales, sujetas, precisamente, al relieve. Es por ello que al pie oriental de la Cordillera de la Costa nos encontramos con áreas de mayor sequedad e, incluso, con algunas características de aridez. Los valores regulares de las precipitaciones en la época invernal también varían a lo largo de la cuenca. Para el área de la ciudad de Santiago el promedio se encuentra en torno a los $360 \mathrm{~mm}^{20}$

Por tanto, el prolongado período seco, la concentración de las lluvias en pocos meses y un régimen nivo-pluvial coadyuvaron a la producción y reproducción de escenarios recurrentes de fuentes de peligro, en una sociedad que no logró generar condiciones eficaces que le permitiesen convivir con esas condiciones.

\footnotetext{
19. Sánchez Muñoz, 2015, 75. DGA (en adelante Dirección General de Aguas), 2015, 20. Ramón, 2000, 7.

20. DGA, 2004, 4. La zona central de Chile por el norte se encuentra condicionada por el anticiclón subtropical del Pacífico Oriental; y por el sur con el cinturón de los vientos del oeste (oestes). Esto la convierte en un área de transición geográfica donde el clima presenta una marcada estacionalidad (Rutllant, 2004, 61-62).
} 


\section{La defensa de la ciudad de Santiago en tiempos de inundaciones}

Con el paulatino aumento de migrantes en la ribera norte del río desde finales del siglo XVI tras el desastre de Curalaba $(1598)^{21}$, se inició un lento proceso de urbanización de La Chimba, área exclusiva de grandes extensiones agrícolas ${ }^{22}$. Así, el río Mapocho se convirtió rápidamente en el geosímbolo por referencia de la frontera social, una circulación de productos, ideas e imaginarios entre el norte y el sur de la ciudad (véase Figura $\mathrm{N}^{\circ} 1$ ) dad, por lo cual cuando se dio este tipo de escenarios, donde las amenazas detonaron en procesos de desastre, los sistema natural y social entraron en conflicto. ${ }^{24}$.

Una de las amenazas más recurrentes fueron las crecidas del Mapocho ya que la ciudad se levantó en el mismo lecho del río. Como su caudal está condicionado por el tiempo y los deshielos cordilleranos, y que por lo general se mantiene bastante escaso, en tiempos de lluvias torrenciales o de deshielos cordilleranos aumenta considerablemente. La documentación colonial nos muestra las reiteradas representaciones de la ciudad para la defensa de esta frente a las inundaciones. Estos

Figura $\mathrm{N}^{0}{ }^{1}$. "Plan de la ville de Santiago capitale du Royaume de Chili scituée par 33d. 40'de lati.de australe a 28 lieues du port de Valparaisso dans la Mer du Sud" del francés Amédée Frezier

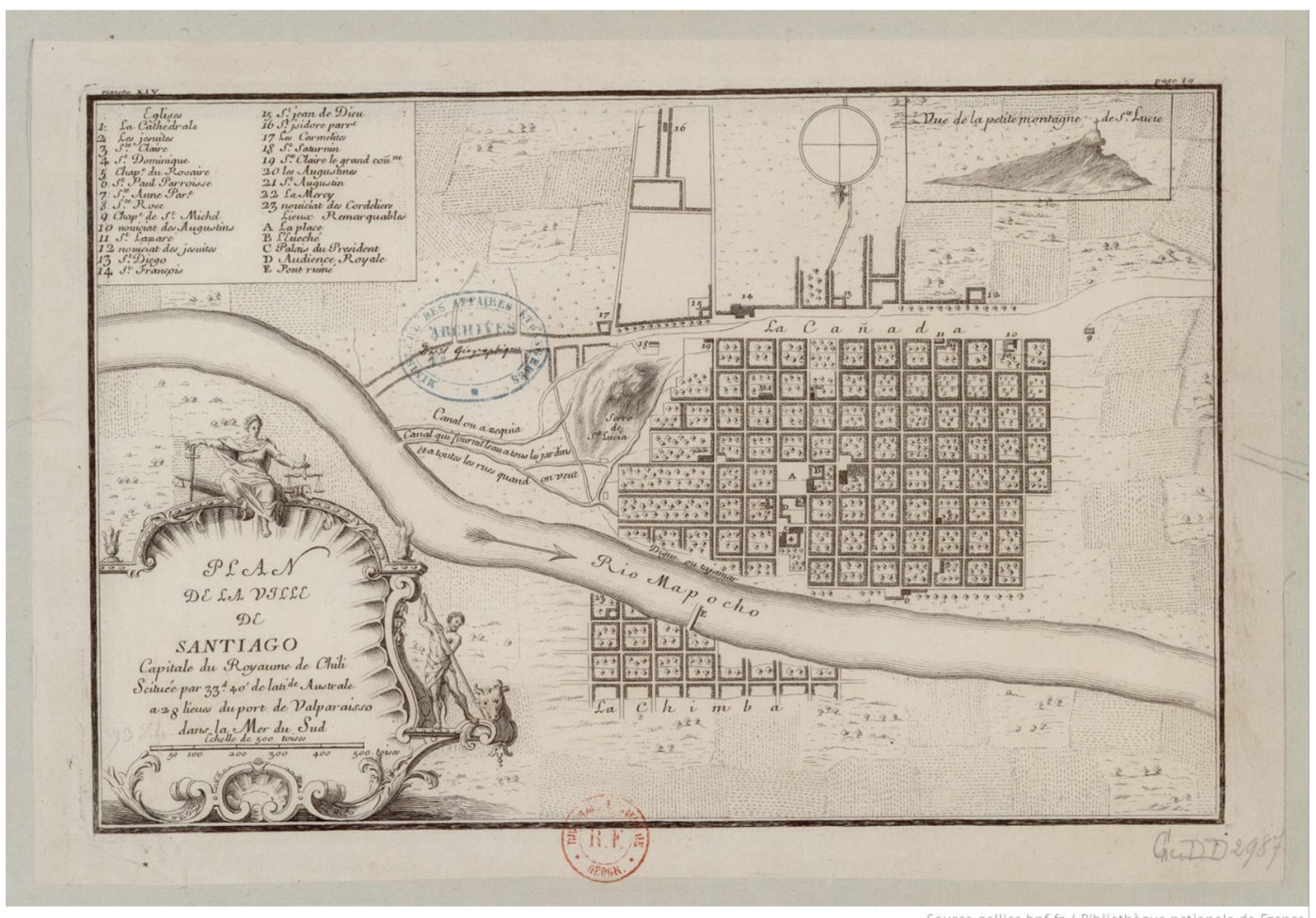

Fuente: Frezier, 1716, 88-89. ${ }^{23}$

Como un espacio de asentamiento estratégico, el Mapocho se transformó en una variable esencial en la estructuración material de la ciudad así como cultural, social y económica. La ocupación de las zonas inundables, convirtieron, sin duda, al proceso natural de las inundaciones fluviales en un riesgo para la socie-

\footnotetext{
21. Corresponde a uno de los momentos más álgidos del conflicto entre la Corona española y los araucanos. El 23 de diciembre de 1598, esta comunidad indígena destruyó las ciudades españolas de Valdivia, la Imperial, Cañete, Arauco, Osorno, Villarrica y Angol.

22. El poblamiento, incluso, iniciaría desde la década de 1560 con el establecimiento de los indígenas yanaconas andinos (Valenzuela Márquez, 2010, 204. Díaz Plá, 2012, 5).

23. Tomado de: https://gallica.bnf.fr/ark:/12148/btv1b8596605s/f1.item.r=Frezier
}

escenarios condicionaron la relación de los vecinos y pobladores de la ciudad de Santiago con el medioambiente, aunque no fue el único factor.

La ciudad de Santiago terminó convirtiéndose en el centro urbano más importante de la Capitanía General de Chile, sede de los sistemas de poder político y religioso, toda vez que consiguió que la residencia del gobernador se trasladara desde Concepción, la instalación de la Real Audiencia en 1609, la presencia de un cabildo que hasta bien entrado el siglo XVIII tenía competencias desde el río Choapa al norte hasta el Maule en el

\footnotetext{
24. Rojas et. al., $2014,178$.
} 
sur, y el dominio de las principales instituciones típicas de la monarquía española a partir las reformas borbónicas. Esto también implicaba un gran poderío económico provisto de grandes zonas de cultivo y de uno de los puertos más importantes, el de Valparaíso. Además de ser una de las ciudades más pobladas en el otrora Reino de Chile.

En este contexto, desde los inicios del proceso de conquista liderado por Pedro de Valdivia en el siglo XVI, la ciudad fue construyendo una manera de relacionarse con uno de los principales referentes geográficos de aquel valle. El Mapocho supuso un medio que permitió estructurar y pensar la ciudad, y al mismo tiempo se convirtió en una amenaza. Su desbordamiento durante lluvias torrenciales y deshielos cordilleranos fue el aliciente para que aquel cauce y sus aguas rápidamente permitieran pensar en una estrategia defensiva. Esta vez no por el conflicto con los araucanos para lo cual se forjaría material y simbólicamente una frontera imponente a partir del río Biobío, sino para evitar que las aguas del Mapocho se metieran en la ciudad y afectaran su circuito de abastecimiento ${ }^{25}$. Así, el Mapocho sería percibido como un "enemigo tan poderoso" 26 , que la ciudad manifestaría una lucha constante por controlarlo. Se convirtió en un espacio del que había que defenderse.

Ya desde comienzos del siglo XVII, la construcción de obras defensivas en el río estuvo presente en las discusiones entre las autoridades y los vecinos. Las ideas para la construcción de los tajamares pasaron a ocupar un espacio en los debates del Cabildo a raíz de la inundación de la ciudad tras las lluvias del mes de agosto de $1607^{27}$. Esta idea terminó en manos del maestre de campo Juan de Quiroga y el agrimensor Ginés de Lillo, en tiempos del gobernador Alonso García de Ramón. Así, los primeros y más rudimentarios tajamares se implantaron al año siguiente de la inundación de $1609^{28}$.

Durante la primera mitad del siglo XVII, este tipo de obras dependía prácticamente de la contribución de los vecinos. Sin embargo, en 1619 surgió la iniciativa de incorporar, en los gastos de la ciudad, el ingreso del

25. "[el Mapocho a] ynundado barias beces la ciudad con daños muy considerables y tenemos siempre ynminente el peligro en sus avenida de ybierno con las llubias y de verano con las nieves que se derriten en la cordillera" Archivo General de Indias (en adelante AGI), Chile, 27, f. 2v, Santiago, 24 de octubre de 1666.

26. Biblioteca Nacional de Chile. Biblioteca Americana José Toribio Medina, Manuscritos (en adelante BNBMMss), 182, pza. 4030, 222r, Santiago, 15 de abril de 1726.

27. Actas del Cabildo de Santiago (en adelante ACS), XXIV, 53. Santiago, 13 de agosto de 1607.

28. ACS, XXIV, 163. Santiago, 12 de febrero de 1610. peso de balanza por acuerdo del 30 de agosto ${ }^{29}$; impuesto que se suprimió a raíz del sismo de $1647^{30}$. Tras una serie de diferencias entre la ciudad y los cosecheros, el monarca español autorizó retomar el cobro del impuesto por medio de real cédula del 20 de julio de 1663 para solventar el estado ruinoso de las obras de públicas ${ }^{31}$. En lo que restó del siglo XVII y durante el siglo XVIII, el ramo de balanza se incorporó en las discusiones y disputas entre las autoridades locales y monárquicas sobre la obtención de recursos para las reparaciones y construcciones de las obras, en especial para aquellas de carácter hidráulico como los tajamares y el canal San Carlos (véase Figura $\left.\mathrm{N}^{\circ} 2\right)^{32}$.

Como se puede apreciar, las construcciones para evitar que el río Mapocho inundara la ciudad ocuparon un espacio privilegiado dentro de las preocupaciones de los santiaguinos ya desde comienzos del siglo XVII. La misma dinámica se sostuvo a los largo de la siguiente centuria, incluso más allá de las acciones contingentes como respuesta a eventos específicos.

En efecto, durante los primeros años del siglo XVIII no se advirtieron inundaciones fluviales de magnitud en Santiago. A pesar de ello, estas ya resultaban en amenazas para la ciudad. Durante la sesión del 1 de julio de 1712 del Cabildo de Santiago, el procurador general propuso que debido a las "cresientes y abenidas del Rio desta Ciudad" 33 que habían ocasionado graves perjuicios por los daños en solares censados, apremiaba la celeridad de las autoridades en orden a realizar los reconocimientos necesarios para llevar a cabo las reparaciones del tajamar y las tomas de agua del río.; ya unos años antes, durante la sesión del 1 de julio de 1707, se señaló que don Santiago de Larraín sostuvo la idea de reparar los cestones que estaban destinados para evitar que el río "se arrim[ara] a esta ciudad" ${ }^{34}$, y que igualmente era conveniente reparar los que el último temporal había arruinado, y con ello no solo se evitarían las inundaciones sino que se recuperarían el resto de cestones existentes. Se encomendó al alguacil mayor, don Cristóbal Dongo, para que reconociese el estado de

\footnotetext{
29. ACS, XXV, 344-345, Santiago, 30 de agosto de 1619 .

30. AGI, Chile, 27, f. 2v, Santiago, 24 de octubre de 1666. ACS, XXXIII, 302-303, Santiago, 18 de septiembre de 1648.

31. Guarda, 1978, 155. Ramón y Larraín, 1982, 299.

32. Archivo Nacional Histórico, Chile (en adelante ANH), Capitanía General, 721, pza. $53,203 v, 10$ de junio de 1718. BNBMMss, 291, pza. 8702, 195, Buen Retiro, 12 de Julio de 1739. BNBMMss, 291, pza. 8719, 287-288, Buen Retiro, 19 de junio de 1748. BNBMMss, 292, pza. 8820, 223-224, Madrid, 11 de julio de 1767. ANH, Capitanía General, 798, pza. 34, 182. Aranjuez, 26 de junio de 1778.

33. ACS, XLVII, 166, Santiago, 1 de julio de 1712.

34. ACS, XLVI, 107, Santiago, 1 de julio de 1707.
} 
Figura No2. Proyecto del Canal del Maipo al Mapocho por el padre Petri, arquitecto de la Compañía de Jesús, 1742.

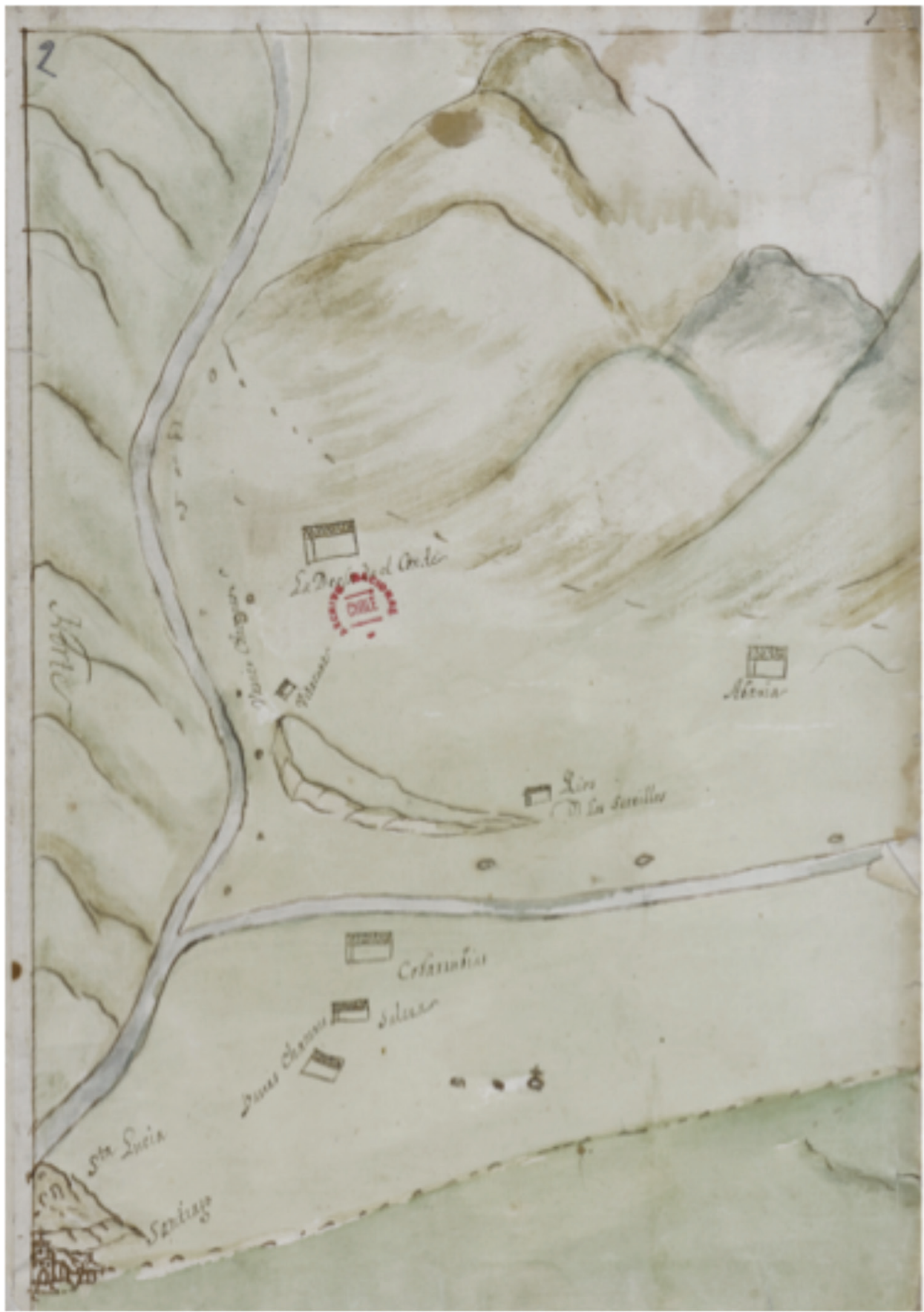

Fuente: ANH, Mapoteca, MAP No 172

las ruinas y diera cuenta del gasto necesario al Cabildo. Ya en la sesión previa del 25 de junio se acordó que el regidor de turno realizara un reconocimiento de las distintas acequias y puentes de la ciudad, en tanto lo necesitaban para atender sus reparos luego de las lluvias de invierno ${ }^{35}$. Estas medidas resguardarían a los vecinos de la ciudad de los ahogamientos, uno de los

35. ACS, XLVI, 106, Santiago, 25 de junio de 1707. peligros más comunes, y garantizarían el abastecimiento ininterrumpido de los alimentos.

Sin embargo, entre 1723 y 1783 tuvieron lugar las avenidas más importantes del siglo XVIII en la ciudad de Santiago. La de 1723, 1748 y 1783 fueron las tres más importantes de todo ese período, anegando la ciudad en reiteradas oportunidades bien por lluvias torrenciales o por deshielos cordialleranos, arruinando de paso gran parte de la 'defensa' de la ciudad, además de arruinar 
las cosechas, provocar la pérdida de ganado y afectar a muchos vecinos. El gobierno local debatió en sus sesiones ordinarias y algunas extraordinarias los medios para solventar la ruina de la ciudad y, especialmente, el reparo de los tajamares, una de las obras hidráulicas de Santiago de mayor envergadura durante la época colonial. Incluso, en el historial de reparaciones y ejecuciones de las obras de los tajamares, sería después de 1765 cuando dichas obras defensivas cobraron un impulso de gran envergadura ${ }^{36}$.

En medio de discusiones sobre el levantamiento indígena en Arauco y las pésimas condiciones del armamento, el 17 de mayo de 1723 el Cabildo de Santiago dio cuenta de una fuerte avenida del Mapocho por lo que las autoridades discutieron sus preocupaciones frente al fenómeno hidrometeorológico y la posibilidad de anegación de la ciudad. La preocupación central de estas discusiones fue la defensiva. La necesidad de reparar los daños ocasionados por la crecida fluvial, especialmente en los emblemáticos tajamares. El río, como resultaba de la experiencia en los años pasados, amenazaba "graves perjuicios" porque de no atenderse los reparos que necesitaban las obras de defensa, la ciudad "padecerá inundación y ruina" ${ }^{37}$.

En las discusiones del 17 de diciembre de 1728 el corregidor don Pedro de Ureta representó que "por haberse arrimado al estribo [el río de la ciudad] que mira para la Chimba del puente y que estaba en términos de que se comiese el dicho estribo en que se podía experimentar grave daño" 38 , condujo a que "la gente miliciana que son indios cuscos, negros y mulatos pasasen al reparo desto" 39 pero que la ciudad no tenía las herramientas necesarias para las reparaciones. Los cabildantes acordaron la compra de 12 arcones e igual cantidad de palas y que el procurador general se dirigiese a la Junta de Balanza con testimonio de lo acordado para que se liberara el importe.

Así sucedería en 1743, cuyas avenidas destruyeron todas las obras preventivas realizadas con anterioridad. Los pies de cabra que se habían dispuesto fueron arruinados, según se señaló en la sesión del 19 de septiembre de 1744. En dicha sesión, el corregidor Juan Francisco de Larraín y de la Cerda señaló que con el reconocimiento que realizó al corte que se le dará al Mapocho a la altura de la casa del capitán Francisco Vivancos, más arriba del tajamar para dividirlo “...y evitar de ese

\footnotetext{
36. Guarda, 1993, 188.

37. ACS, vol. LI, 27, Santiago, 21 de mayo de 1723,

38. ACS, vol. LI, 338, Santiago, 17 de diciembre de 1728.

39. ACS, vol. LI, 338, Santiago, 17 de diciembre de 1728.
}

modo la inundación que amenaza y que se experimentó el año pasado con las avenidas del verano" ${ }^{40}$. Ese reconocimiento de la caja del río se había convenido ya en sesión del 4 de julio del mismo año, justo donde “...se ha hecho un banco que impele las aguas para la ciudad y puede causar daño con las avenidas" ${ }^{41}$ para que lo llevasen a cabo los señores Antonio Gutiérrez de Espejo, alguacil mayor, a Francisco de Tagle y Bracho, alférez real, y a Alejandro de Salamanca, el alcalde de Aguas.

Para esta labor se solicitó sacar del ramo de balanza la cantidad de 300 pesos, recalcando los cabildantes que ese había sido el monto utilizado anteriormente con los reparos que en su momento fueron necesarios de ejecutar. El gasto sería distribuido en concepto del “...alquiler de peones, costear herramientas, pagar un sobrestante porque no era practicable que el señor Capitular a quien se le encomendase estuviese en el pedregal de sol a sol..." ${ }^{42}$, encargándose la administración a Gutiérrez de Espejo. Este último presentó la cuenta del importe librado para dichos reparos e hizo constar en la misma que gastó seis pesos y cuatro reales más de lo aprobado inicialmente. La presentación de la cuenta fue recibida y se mandó al síndico mayordomo para que, por la gestión realizada en dichos reparos, se le diera al don Gutiérrez de Espejo “...los seis pesos y cuatro reales del alcance, y veinte y cinco pesos más que se le asignan para herraduras de su caballo..."

Esas inundaciones no despertaron tanto interés como sí las reparaciones del tajamar. En sesión del 27 de septiembre de 1744 el síndico mayor de los propios de la ciudad, don Francisco José de Toro, rindió cuentas del gasto referido a la obra del reparo sin concluir del tajamar del Mapocho, con un importe de 543 pesos 1 real y medio asumido a crédito de dicho mayordomo. Para que el trabajo hasta entonces realizado no se perdiese, el Cabildo acordó la libranza de 700 pesos para culminar la obra, los cuales incluían la deuda con el síndico mayordomo y la construcción de un puente adyacente a la casa del capitán Marcos Rodríguez ${ }^{44}$.

Estos escenarios, y a pesar de todas las precauciones, no prepararon a los vecinos de Santiago para enfrentar el riguroso invierno de 1748 , que ya desde finales del mes de abril y principios de mayo comenzó a generar numerosos daños. Fue un escenario generalizado de crisis y el río Mapocho no fue el único cauce que se

\footnotetext{
40. ACS, LIV, 79, Santiago, 19 de septiembre de 1744.

41. ACS, LIV, 74

42. ACS, LIV, 79 .

43. ACS, LIV, 82, Santiago, 13 de noviembre de 1744

44. ACS, LIV, 59, 27 de septiembre de 1744.
} 
desbordó. El Aconcagua y el río Chillán fueron escenarios de fuertes inundaciones que arrasaron e intervinieron en la cotidianidad de aquellas comunidades. El 30 de abril fue el turno del Mapocho y esta vez no solo destruyó los tajamares sino también el puente ubicado frente al convento de la orden de los franciscanos, el cual permitía articular el centro de la ciudad con la zona norte. Plazas, calles y edificios se vieron afectados; las acequias se taparon ocasionando un grave problema de escasez hídrica ${ }^{45}$.

Otra inundación importante fue la del 7 de noviembre de 1764. El Cabildo reunido dio cuenta de que por motivo de la gran cantidad de nieve acumulada que se generó por el 'vigoroso invierno', y por el “influjo del sol y sus calores que derriten y disuelven dichas nieves", la ciudad está en riesgo por la avenida del río con gran abundancia de agua. De acuerdo con el Cabildo, ya desde el día 5 del mismo mes, y a pesar de los intentos constantes "para contener la violencia de dicho río en su creciente", se comenzó a notar la avenida, por lo que en el mismo momento se dispuso de "piedras y horcones para poner y reforzar los pies de cabra y otros reparos" $"$.

A pesar de los esfuerzos no lograron contener las aguas que se vieron impulsadas por el cauce de la acequia del Molino de San Pablo, la cual fue formada "sin parapeto" para hacerle llegar el agua al molino, con lo cual no se tomó en cuenta "la dificultad que habría para remediar cualquier daño" ${ }^{" 77}$. El Cabildo, en conformidad con lo representado por el corregidor don Luis Manuel de Zañartu e Iriarte, acordó trasladarse a las riberas del río junto con el escribano Justo del Águila y Vicente Marcelino de la Peña, quien había sido alarife de la ciudad en 1763 y, por tanto, se sumó a la comisión en reemplazo del que ostentaba ese puesto en ese momento que por motivos no especificados estaba ausente. Los daños fueron evidentes y se llegó a la conclusión que el peligro que representaba las condiciones del río era grave por la parte que daba a la casa de don Antonio de Segovia, vivienda que quedaría en ruina, al igual que las adyacentes, incluso la plaza mayor de la ciudad, si no se apresuraban los reparos. Además de correr riesgo, en la rivera del frente, "la hacienda y el barrio de La Cañadilla" 48.

Se comisionó al procurador general para que acudiese a la Junta de Balanza y se librasen 400 pesos, o lo que consideren conveniente, para comenzar las obras. Tam-

\footnotetext{
45. ACS, LV, 41, Santiago, 8 de noviembre de 1748.

46. ACS, LVI, 136, Santiago, 7 de noviembre de 1764.

47. ACS, LVI, 136, Santiago, 7 de noviembre de 1764.

48. ACS, LVI, 137.
}

bién se acordó tapar su bocatoma en vista de que los pies de cabra no eran suficientes para evitar los daños que podía ocasionar la acequia del Molino de San Pablo, ya que "abierto el cauce ha de llamar siempre al río" 49 .

Este panorama continuaría en la década de 1780. El Cabildo de Santiago en sesión del 7 de marzo de ese año hizo referencia a avenidas extraordinarias experimentadas por la ciudad desde el 30 de abril y los primeros días del mes de mayo de 1779, cuyos daños ocasionados en los tajamares se debieron “...por la gran excavación que hacen las aguas en el terreno arenoso en que están fundados..." ${ }^{50}$. Aquellas avenidas reflejaron la ineficacia de las obras defensivas y no sería hasta cuatro años después, luego de la Gran Avenida de 1783, que se plantearía una revisión de aquellas obras.

El siglo XVIII, en relación con los eventos climáticos extremos, cerraría con la gran avenida del 16 de junio de 1783. Después de un par de días de prolongadas lluvias, los daños en la ciudad fueron graves y los tajamares del Mapocho nuevamente quedaron destruidos, con lo cual las chacras de los alrededores de la ciudad se vieron afectadas, algunas edificaciones civiles y eclesiásticas se arruinaron, los molinos se destruyeron y gran cantidad de ganado pereció ${ }^{51}$.

Para su reparación se recurrió, en ese momento, a Joaquín Toesca, uno de los actores más importantes, artífice de muchas de las grandes obras de la segunda mitad del siglo. El costo de la misma se sacaría del tradicional ramo de balanza, pero además se incorporaron otras contribuciones. De esta manera, superados los debates entre los integrantes de la Junta de la Real Hacienda, y a pesar del descontento de los comerciantes, se estableció en 1788 por un tiempo de seis años el derecho de un peso por cada zurrón de yerba mate proveniente de Paraguay y también para el caso del azúcar que llegaba desde Lima ${ }^{52}$. Esta avenida se convirtió en la más grande del siglo XVIII y se tradujo en un desastre de considerables dimensiones.

\footnotetext{
49. ACS, LVI, 137.

50. ACS, LVII, 162, Santiago, 7 de marzo de 1780.

51. ANH, Capitanía General, 190, 456-457 v, Santiago, 11 de diciembre de 1784. ANH, Capitanía General, 952, pza. 1, 1-22v, Santiago, 30 de junio de 1783. Urrutia y Lanza, 1993, 69-70.

52. BNBMMss, 205, pza. 5078, 54, Santiago, 8 de noviembre de 1788. ANHCG, 889 , pza. 8,63 , Santiago, 8 de octubre de 1788 . ANHCG, 889, pza. 8,67 Santiago, 16 de octubre de 1788.8 de noviembre de 1788 .
} 


\section{El río Mapocho como espacio de desencuentro en tiempos de sequía}

La ciudad de Santiago construyó una relación con el río Mapocho que la convirtió, como se pudo apreciar a lo largo del siglo XVIII, en un espacio no solo de riesgos y amenazas, sino también en un geosímbolo de desastres. Como espacio de riesgos y de amenazas, el río se tradujo en un lugar de desencuentro que engranaría los cimientos de una proyección identitaria negativa en torno a su curso. No solo no lograba, según la percepción, abastecer a las comunidades que dependían de él, sino también se convirtió en uno de los principales focos de enfermedades durante la época donde sus aguas escurrían escasamente. En efecto, además de las inundaciones, otra de las amenazas más recurrentes fueron las sequías. Para el siglo XVIII se contabilizaron 39 años que fueron afectados por la disminución de las lluvias durante el período invernal ${ }^{53}$. Las autoridades civiles y eclesiásticas frente a estos escenarios desplegaron estrategias que iban desde el ámbito religioso con la organización de rogativas y otras actividades devotas hasta medidas supeditadas a los conflictos sociales por el control del recurso hídrico.

En este sentido, el río Mapocho fue el escenario de acérrimas luchas entre los habitantes de la ciudad por el manejo de sus aguas a través de los sistemas de repartimiento. Así, en tiempos de sequías o de escasez hídrica como resultado de la distribución del recurso, las autoridades establecieron impositivamente los turnos de agua dedicados a los sistemas de riego y en tiempos en que el vital líquido resultaba escaso los vecinos de la ciudad recurrieron a prácticas transgresoras de las normativas vigentes: la desviación, rotura de las acequias y sustracción del líquido a través de los ladrones de agua y albañalesfue de lo más común ${ }^{54}$. Acciones todas ellas que terminaron convirtiéndose en prácticas recurrentes en períodos de sequías ${ }^{55}$.

En este caso, y a diferencia de la estrategia defensiva anteriormente expuesta, el agua del río Mapocho se convirtió en un recurso natural ya no solo estratégico sino también disputado, en especial entre los hacendados, comerciantes y las autoridades locales y monárquicas, civiles y eclesiásticas. Entre los episodios más importantes al res-

\footnotetext{
53. Noria Peña, 2018, 143-144.

54. Los ladrones de agua, de acuerdo con el alarife de la ciudad de Santiago Jorge Lanz "...son aquellos a quienes no se les ha señalado entrada y salida por el Alarife, y que no son conforme a la traza que está mandada se tenga con las aguas...". ACS, XXXII, 192, Santiago, 1 de marzo de 1758.

55. Noria Peña, 2018, 169.
}

pecto, se pueden advertir las sequías de 1725-1726, 17571758 y 1772. Con la sequía de 1757, por ejemplo, se discutió en la ciudad sobre la gran cantidad de tomas que se habían realizado sin autorización y los perjuicios que esto generaba no solamente entre los mismos vecinos sino también para la limpieza de la ciudad que se veía afectada por los múltiples derramamientos de las acequias ${ }^{56}$.

A pesar de las regulaciones y el control del recurso y su distribución, los conflictos formaron parte recurrente de la manera en que los vecinos de Santiago respondieron frente a escenarios de escasez hídrica. Las disputas que se originaban podían terminar en enfrentamientos físicos entre los afectados o en querellas por el dominio del agua.

Por ejemplo, con la sequía de 1725 se estableció el sistema de turno entre los hacendados localizados en el pago de Ñuñoa y los de Renca. A pesar de ello, la "sequedad del tiempo" fue prolongada y la población decidió sustraer el agua por su cuenta en "cuadrillas y armados" ${ }^{57}$. Estas prácticas se sostenían con la denuncia por parte de los afectados de los sistemas de turnos implantados. En los períodos de prolongadas sequías, como los mencionados anteriormente, se evidenció el descontento de los vecinos.

En 1757 los hacendados de la parte de arriba presentaron sus respectivas quejas al bando sobre los turnos de agua publicado el 28 de septiembre de ese año que les dejaba a ellos dos días de regadío y cinco a los hacendados de la parte de abajo. En las quejas no solo manifestaron su descontento generalizado sino que lo sustentaron al señalar como injusto el sistema ya que no tomaba en cuenta la cantidad real de agua que requerían no solamente por presentar una mayor demanda sino también por contar con condiciones medioambientales desventajosas. Establecieron que ellos poseían 84 chacras, sin contabilizar aquellas que solamente tenían árboles frutales, en contraposición con los de la parte de abajo que tenían solamente $32^{58}$.

Las autoridades no asumieron la misma postura. Para 1768 , en medio de discusiones en torno al proyecto de trasvase de las aguas del río Maipo al Mapocho, uno de los proyectos hidráulicos de mayor envergadura del siglo $\mathrm{XVIII}^{59}$, el cabildo de Santiago señaló que en los meses

56. ACS, XXXII, 192, Santiago, 1 de marzo de 1758.

57. ACS, LI, 225, Santiago, 13 de agosto de 1726.

58. ANH, Capitanía General, 955, pza. 6, 154- 157, Santiago, 31 de octubre de 1757.

59. Con la sequía de 1717 comienzan las discusiones sistemáticas para el proyecto de trasvase de las aguas del Maipo al Mapocho. Los cabildantes de la ciudad insistían en las ventajas para la expansión de la frontera agrícola y para suplir la falta de agua cuando disminuía el caudal del Mapocho. Para ese momento el proyecto no se concretó y tras reiteradas discusiones que se retomaban en tiempos de sequía $(1725,1742-1746,1757,1761-1764$, 
de escasez de agua, ya por la estación veraniega o por ausencia prolongada de lluvias durante los meses de invierno, los "golpes, y pleytos sobre la preferencia de regar sus respectivas heredades..." eran comunes y quienes salían beneficiosos de estos escenarios eran aquellos hacendados ubicados en la parte de arriba, razón por la cual ellos en la práctica se convertían en "Dueños del Agua" ${ }^{\text {. }}$

Los de la parte de abajo no quedaban exentos de reclamos. El marco jurídico en torno al agua establecía que la distribución de la misma en la ciudad, es decir, el agua de las viviendas y las comunidades, debía ser continua. De manera que, las acequias que atravesaban Santiago y la pila de la plaza tenían que mantenerse con un flujo regular de agua. Por lo que en tiempos de sequías, cuando se generaban acciones fuera del marco regulatorio establecido por las autoridades locales por parte de los propietarios de extensiones agrícolas de las áreas aledañas, los regidores de turno encargados de la alcaldía de aguas y el procurador de la ciudad insistían en lo perjudicial para el consumo urbano, en especial, cuando los hacendados de la parte de abajo afectaban la libre circulación por las acequias de la ciudad de dichas aguas. Para 1732, por ejemplo, el Cabildo se quejaba de que los vecinos de la parte de abajo del Mapocho "desbarrancaban la toma de la ciudad"61 , lo cual dificultaba que el agua circulara sin dificultad por las acequias de la ciudad.

Otro aspecto importante de la disminución de las aguas del Mapocho en tiempos de sequías y en la época de verano fue la asociación que se generó entre las autoridades y la población en general entre estos episodios y la proliferación de enfermedades infectocontagiosas. Los brotes de enfermedades fueron de las amenazas más temidas por la población. Es por esa razón que, en aquellos años donde las lluvias tardaban en aparecer, el procurador de la ciudad, elevando a instancias del Cabildo las preocupaciones de la población, se manifestaba para tomar medidas que evitaran, precisamente, el desarrollo de alguna enfermedad.

Entre los años 1717 y 1718 se ha documentado un período prolongado de falta de lluvias en la región que abarcó la zona central de Chile y generó daños en la agricultura y la ganadería. ${ }^{62}$ En este mismo escenario

$1772,1799,1802)$, la obra comenzaría a funcionar parcialmente desde el 20 de agosto de 1820. ACS, L, 162, Santiago, 5 de noviembre de 1717; ACS, LI, 145, Santiago, 27 de abril de 1725; ACS, LIV, 39, Santiago, 8 de junio de 1742; ACS, LV, 180-181, Santiago, 23 de diciembre de 1757; BNBMMss, 186, pza. 4217, 149; AGI, Chile, 319. 1765.

60. AGI, Chile, 319, 1. 1769.

61. ACS, LII, 136, Santiago, 22 de marzo de 1732.

62. Armando de Ramón y José Manuel Larraín (1982) señalan que, de hecho, entre 1717-1727 fue un período inestable en cuanto a la producción agrícola y que las autoridades, así como comerciantes y productores, no lograron se presentó una falta de trigos candeales, el caudal del Mapocho se vio disminuido y los vecinos de la ciudad se quejaron del brote de viruela que afectaba en $1718^{63}$ Así, en quel contexto se generó una de las discusiones más importantes durante el período colonial en torno a la calidad de las aguas del principal surtidor natural de la ciudad: el Mapocho. El agua de la pila ubicada en la plaza era "pestilencial", de acuerdo con los testimonios de la época, ya que corría "revuelta con puelcura" ${ }^{64}$. A raíz de ello, se consideró que el agua de la pila fuese la de Ramón y no la del Mapocho, por lo que se abrió el debate entre el Procurador General Antonio de Zumeta y el Fiscal en torno a la distribución del ramo de balanza para lograr la conducción del recurso hídrico. ${ }^{65}$ Zumeta en sus argumentos insistió que la "malignidad" de las aguas del Mapocho ocurría cuando disminuía su caudal, lo que incluso llevaba a la muerte de sus peces. Su solicitud fue acompañada, igualmente, por la certificación de los bachilleres Diego de Lasevinat y Miguel Jordán Merino, así como por el informe del médico Ochandiano, quienes confirmaban que el agua del Mapocho no era de buena calidad para el consumo ${ }^{66}$.

Estos escenarios de escasez si bien fueron recurrentes, el miedo en torno a la presencia de las sequías estaba supeditado a las epidemias y la muerte de los ganados, principalmente. ${ }^{67}$ Por ejemplo, el Procurador General Antonio Gutiérrez de Espejo con la sequía que se presentaba en el año de 1754 elevó una petición al Cabildo de Santiago para que se sacara en procesión a San Isidro. En su exposición no solo sostuvo que era constante la escasez de este recurso, sino que además esta se daba como castigo de la Divina Providencia, por ello estaba presente la amenaza de pestes, la muerte del ganado y la infertilidad de las tierras ${ }^{68}$. Para 1759, con motivo de la epidemia que afectaba a la población, se

conseguir soluciones oportunas que permitiesen controlar la situación. Incluso, los cabildantes mostraron gran preocupación por el abasto de trigo blanco a Lima y los usos del trigo candeal, el cual estaba destinado para garantizar el abastecimiento de la ciudad de Santiago. De manera que, solicitaron que no se sacasen aquellos granos de Chile. ACS, IL, 198, Santiago, 17 de noviembre de 1765 .

63. ACS, IL, 198, Santiago, 1 de julio de 1718.

64. Se refieren a un sedimento proveniente del estero Yerba Loca compuesto por distintos sulfatos que durante la primavera es arrastrado por la corriente del Mapocho a raíz de los deshielos cordilleranos. Piwonka, 1999, 395.

65. BNBMMss, 333, pza. 654, 405-408. El informe del Procurador General aparece publicado en Vicuña Mackenna, 1974, 217.

66. ACS, L, 186, Santiago, 26 de febrero de 1718. ANH, Capitanía General, 929, pza. 19, 107r, Santiago, 31 de julio de 1718. BNBMMss, 333, pza. 653, 403404, Santiago, 29 de julio de 1718. BNBMMss, 333, pza. 655, 409-416, Santiago, 2 de agosto de 1718 . BNBMMss, 333, pza. 648, 356-359. BNBMMss, 333 , pza. $654,405-408$.

67. Noria Peña, 2018, 320-322

68. ACS, LV, 116, Santiago, 30 de julio de 1754. 
solicitó una procesión el último día de la novena establecida a Nuestra Señora de La Merced ${ }^{69}$. Este aumento de enfermedades y las muertes en aquel año se dio, según se sostuvo, precisamente por la "sequedad del año", ya que durante el período de invierno ocurrió "una grande escasez de aquellas lluvias regulares" ${ }^{70}$. A este tenor se observó un debate en el cabildo para 1760 , cuando el brote epidémico y la escasez de legumbres fue atribuido a la falta de lluvias, de manera que se decidió la realización de una novena y procesión a Nuestra Señora del Socorro porque cabía esperar "más agudas y violentas enfermedades"71.

Como ha quedado establecido, la ciudad de Santiago para el siglo XVIII estuvo en una recurrente escasez de agua por falta de lluvias y el río Mapocho se convirtió en un escenario de riesgo y amenaza en tiempos de escasez. No obstante, los relatos de viajeros y los escritos de algunos agentes de la monarquía española resaltaron una idea de abundancia de Santiago y de la zona central del Reino de Chile, que se veía reforzada a partir de la exaltación de la gran cantidad de fuentes naturales de agua de sus ríos ${ }^{72}$.

La ciudad de Santiago, como muchas otras de Hispanoamérica, llamó la atención por la gran cantidad de acequias que suponían un complejo sistema de autoabastecimiento a partir de las numerosas huertas ${ }^{73}$, surtidas por el río Mapocho, que en ella se mantenían ${ }^{74}$. Esto generó un discurso en torno a la fertilidad de aquel reino periférico que, sin embargo, entró en conflicto con los periódicos eventos de sequías.

\section{Conclusiones}

El estudio del río Mapocho como espacio de riesgo y amenazas durante el siglo XVIII permitió evidenciarlo como un geosímbolo de desastres frente a eventos climáticos extremos y amenazas biológicas. De esta manera, los vecinos de Santiago y las autoridades percibieron el río como una fuente de diversos peligros de los cuales debían defenderse. Inundaciones, sequías y enfermedades. Los tajamares, el canal San Carlos y los cambios en los usos y distribución del agua se convirtieron en los exponentes de esta relación.

\footnotetext{
69. Esta novena se daba todos los años en el marco de la festividad de la virgen.

70. ACS, LVI, 30, Santiago, 4 de septiembre de 1759.

71. ACS, LVI, 53, Santiago, 18 de abril de 1760.

72. Carvallo y Goyeneche, 1875 [1796], 30.

73. Sánchez-Rodríguez, 2015, 52.

74. Haenke, 1942, 92. Carvallo y Goyeneche, 1875 [1796], 31. Pérez García, 1900, tomo I, 15.
}

En efecto, para el siglo XVIII la presencia de amenazas naturales condujo a distintas discusiones por parte del Cabildo de Santiago que se dedicaron a buscar soluciones a los problemas generados por estas. Los brotes epidémicos, las inundaciones fluviales por deshielos cordilleranos y las sequías fueron variables recurrentes en las reuniones de los cabildantes y condujeron a extendidos debates a los cuales les dedicaron numerosas sesiones.

Las inundaciones en la ciudad de Santiago a lo largo del siglo XVIII se debieron principalmente al desbordamiento del río Mapocho producto de lluvias torrenciales en la temporada de invierno y por los deshielos cordilleranos en primavera. Los daños más recurrentes estuvieron relacionados con las infraestructuras hidráulicas y viarias, como fue el caso de los tajamares del Mapocho y el puente del Maipo. Pero también se intensificaron las acciones referentes a las acequias de la ciudad y al aseo de las mismas, las cuales tuvieron sus espacios de discusión todos los años entre septiembre y noviembre.

Este tipo de escenario, desde la etapa inicial de conquista en los tiempos de Pedro de Valdivia, generó una posición de defensa frente a las inundaciones cuando se mostraba crecido el Mapocho. La mejor defensa al respecto fue la creación de mecanismos para evitar la anegación de la ciudad. Las consecuencias a largo plazo de las avenidas del río significaron un alto costo.

Serían precisamente estos escenarios de inundaciones los que permitieron convertir al río en un geosímbolo de desastres. Las avenidas del Mapocho representaron un peligro tanto para el imaginario social como institucional de Chile. El río personificó un ente frente al cual se debía producir estrategias que permitieran a los actores políticos, sociales, económicos, institucionales y a la población en general protegerse y detener sus embates durante las épocas en las cuales su caudal aumentaba. En este sentido, el principal río que atravesaba la ciudad significó un problema para los incipientes asentamientos de la Corona, al mismo tiempo que comenzaron a producirse distintas obras hidráulicas como sistemas defensivos.

La importancia histórica de los ríos es indudable, y cada vez más la historiografía se interesa por asumirlos como objetos de estudio. Son parte de la realidad factual y abstracta. Además de ser recursos naturales también son el resultado del imaginario colectivo que se apropia de ellos y les otorga historicidad. 


\section{BIBLIOGRAFÍA}

Altez, R. 2016: Historia de la vulnerabilidad en Venezuela: siglos XVIXIX. Madrid (España), Editorial Universidad de Sevilla, Consejo Superior de Investigaciones Científicas, Diputación de Sevilla.

Altez, R. 2014: Historia de la vulnerabilidad en las regiones hoy venezolanas. Terremotos y sociedad 1530-1872, tesis doctoral, Universidad de Sevilla, Sevilla (España).

Altez, R. 2009: "Ciclos y sistemas versus procesos: aportes para una discusión con el enfoque funcionalista sobre el riesgo", Desacatos, 30, 111-128.

Beck, U. 2006: La sociedad del riesgo. Hacia una nueva modernidad. Barcelona, Ediciones Paidós.

Bonnemaison, J. 1992: "Le territoire enchanté: Croyances et territorialité en Mélanésie", Géographie et cultures, 3, 71-88. https:// doi.org/10.4000/gc.6918

Carvallo y Goyeneche, V. 1875 [1796]: Descripción histórico-geográfica del Reino de Chile, en Colección de historiadores de Chile y documentos relativos a la historia nacional, vol. IX. Santiago (Chile), Imprenta de la Estrella de Chile.

Castillo Fernández, S. 2014: El río Mapocho y sus riberas. Espacio público e intervención urbana en Santiago de Chile (1885-1918). Santiago (Chile), Ediciones Universidad Alberto Hurtado.

Crosby, A. 1988: Imperialismo ecológico. La expansión biológica de Europa, 900-7900. Barcelona (España), Editorial Crítica.

Crosby, A. 1972: The Columbian Exchange, Biological and Cultural Consequences of 1492. Westport (United States), Greenwood Press.

Díaz Plá, R. 2012: "Imaginario social de la cartografía histórica del barrio de La Chimba. Poder, significación y simbolismo", Revista Chilena de Antropología Visual, 19, 1-19.

Dirección General de Aguas (DGA). 2015: Atlas del Agua. Chile 2016. Santiago (Chile), Dirección General de Aguas, Ministerio de Obras Públicas. http://www.dga.cl/DGADocumentos/Atlas2016parte1-17marzo2016b.pdf

Dirección General de Aguas (DGA). 2004: Diagnóstico y clasificación de los cursos y cuerpos de agua según objetivos de calidad. Cuenca del Río Maipo. Santiago (Chile), Dirección General de Aguas, Ministerio de Obras Públicas. http://portal.mma.gob.cl/ wp-content/uploads/2017/12/Maipo.pdf

Fernández de Oviedo y Valdés, G. 1855: Historia general y natural de las Indias, islas y tierra-firme del Mar Océano, Tercera Parte, tomo IV. Madrid (España), Imprenta de la Real Academia de la Historia.

Frezier, Amédée. 1716: Relation du voyage de la mer du sud aux côtes du Chily et du Perou, fait pendant les années 1712, 1713 \& 1714. Paris (France), Jean-Geoffrey Nyon, Quat de Conti, au coin de la rue Guenegaud, au Nom de Jesus-Etienne Ganeau, rue Saint Jacques, aux Armes de Dombes, vis-á-vis la Fontaine de $\mathrm{S}$. Severin-Jacque Quillau, Imprimeur-Juré-Libraire, rue Galande, aux Armes de l'Université.
García Acosta, V. 2004: "La perspectiva histórica en la antropología del riesgo y del desastre, acercamientos metodológicos", Relaciones. Estudios de historia y sociedad, 97, 124-142.

Gay, C. 1846: Historia física y política de Chile. Tomo 1: Documentos sobre la historia, la estadística y la geografía. París (Francia), En casa del autor; Chile, Museo de Historia Natural de Santiago.

Gómez Alcorta, A.; Prado Berlien, C. y Ocaranza Bosio, F. J. 2012: "Registro arqueológico y contextualización histórica de los Tajamares del río Mapocho, Chile", HISTOReLo. Revista de Historia Regional y Local, 8, 275-315. https://doi.org/10.15446/ historelo.v4n8.30351

Guarda, G. 1993: "Las obras hidráulicas en el Reino de Chile", en Ministerio de Obras Públicas y Urbanismo, Obras Hidráulicas en América colonial. Madrid (España), CEHOPU, Centro de Estudios históricos de Obras Públicas y Urbanismo-CEDEX, Centro de Estudios y Experimentación de Obras Públicas, 181-198.

Guarda, G. 1978: Historia urbana del Reino de Chile. Santiago (Chile), Editorial Andrés Bello.

Haenke, T. P. 1942: Descripción del Reyno de Chile. Santiago (Chile), Editorial Nascimento.

Huerta García, T. 1862: Relacion de la inundacion que hizo el rio Mapocho de la ciudad de Santiago de Chile en el Monasterio de Carmelitas, titular de San Rafael, el dia 16 de julio [junio] de 1783. Santiago (Chile), Imprenta del Ferrocarril.

Kiple, K. F. 1993: "Disease Ecologies of the Caribbean", en Kiple, K. F. (ed.): The Cambridge World History of Human Disease. Cambridge (United Kingdom), Cambridge University Press, 497-504. doi.org/70.1017/CHOL9780521332866.059

Mellafe, R. 1980: "El acontecer infausto en el carácter chileno: una proposición de historia de las mentalidades", Atenea. Revista de Ciencia, Arte y Literatura, 442, 121-128.

Newman, M. T. 1976: "Aboriginal New World Epidemiology and Medical Care, and the Impact of Old World Disease Imports", American Journal of Physical Anthropology, 45, 667-672. https:// doi.org/10.1002/ajpa.1330450333

Noria Peña, A. 2018: Estrategias frente a eventos climáticos extremos en la época colonial hispanoamericana. El caso de las sequías en Santiago de Chile en la etapa borbónica, tesis doctoral, Universidad Autónoma de Chile/Universidad de Sevilla, Santiago/Sevilla (Chile/España).

Olivera Poll, A. 1988: "La percepción histórica del riesgo en el espacio geográfico americano", Estudios Geográficos, 191, 241-254.

Onetto, M. 2017: Temblores de tierra en el jardín del Edén. Desastre, memoria e identidad. Chile, siglos XVI-XVIII. Santiago (Chile), Dirección de Bibliotecas, Archivos y Museos, Centro de Investigaciones Diego Barros Arana

Palacios Roa, A. 2015: Entre ruinas y escombros, los terremotos en Chile durante los siglos XVI al XIX. Valparaíso (Chile), Ediciones Universitarias de Valparaíso. 
Pérez García, J. 1900: Historia natural, militar, civil y sagrada del reino de Chile en su descubrimiento, conquista, gobierno, población, predicación evangélica, erección de catedrales y pacificación, en Colección de historiadores de Chile y documentos relativos a la historia nacional, vols. XXII-XXIII. Santiago (Chile), Imprenta Elzeveriana.

Piwonka, G. 1999: Las aguas de Santiago de Chile 1541-1999. Tomo 1: Ios primeros doscientos años, 1547-1741. Santiago (Chile), Ediciones de la Dirección de Bibliotecas, Archivos y Museos, 1999.

Ramón, A. de. 2000: Santiago de Chile (1541-1991). Historia de una sociedad urbana. Santiago (Chile), Editorial Sudamericana Chilena.

Ramón, A. de. y Larraín, J. M. 1982: Orígenes de la vida económica chilena, 1659-1808. Santiago (Chile), Centro de Estudios Públicos.

Rojas, O., Mardones, M., Arumí, J. L. y Aguayo, M. 2014: “Una revisión de inundaciones fluviales en Chile, período 1574-2012: causas, recurrencia y efectos geográficos", Revista de Geografía Norte Grande, 57, 177-192. https://doi.org/10.4067/S071834022014000100012

Rutllant, J. A. 2004: "Aspectos de la circulación atmosférica de gran escala asociada al ciclo ENOS 1997-1999 y sus consecuencias en el régimen de precipitación en Chile central," en Avarias, S., Carrasco, J., Rutllant, J: y Yáñez, E (Eds.), El Niño-La Niña 1997-2000. Sus Efectos en Chile. Valparaíso (Chile), CONA, 61-76.
Sánchez Muñoz, A. 2015: Geografía de Chile. Un enfoque físico, humano y económico. Santiago (Chile), Editorial Bibliográfica Internacional Ltda. Sánchez-Rodríguez, M. 2015: "Agua, horticultura y urbanismo en una ciudad americana. Santiago de Chile en la época virreinal", Agua y Territorio, 5, 38-53. https://doi.org/70.17567/at.v0i5.2533

Stehberg, R. y Sotomayor, G. 2012: "Mapocho incaico", Boletín del Museo Nacional de Historia Natural, 61, 85-149.

Urrutia de Hazbun, R. y Lanza Lazcano, C. 1993: Catástrofes en Chile 1547-1992. Santiago (Chile), Editorial La Noria.

Valenzuela Márquez, J. 2010: "Devociones de inmigrantes. Indígenas andinos y plurietnicidad urbana en la conformación de cofradías coloniales (Santiago de Chile, siglo XVII)", Historia, 43, 203-244. https://doi.org/10.4067/S0717-71942010000100006

Vicuña Mackenna, B. 1877: Ensayo histórico sobre el clima en Chile (desde los tiempos prehistóticos hasta del gran temporal de julio de 1877). Valparaíso (Chile), Imprenta del Mercurio.

Vicuña Mackenna, B. 1974: Médicos de antaño. Santiago (Chile), Editorial Francisco de Aguirre. 